\title{
Multifaceted Neuro-Regenerative Activities of Human Dental Pulp Stem Cells for Functional Recovery after Spinal Cord Injury
}

\author{
Akihito Yamamoto, Kohki Matsubara, Kiyoshi Sakai, \\ Fumiya Kano and Minoru Ueda
}

Additional information is available at the end of the chapter

http://dx.doi.org/10.5772/58906

\section{Introduction}

Spinal cord injury (SCI) often leads to persistent functional deficits, due to loss of neurons and glia and to limited axonal regeneration after injury. Recently, three independent groups have reported that transplantation of human adult dental pulp stem cells (DPSCs) and stem cells from human exfoliated deciduous teeth (SHEDs), into the acute, sub-acute or chronic phase of rat or mouse SCI resulted in marked recovery of hindlimb locomotor functions. This review summarizes the primary characteristics of human dental pulp stem cells and their therapeutic benefits for SCI treatment. Experimental data from a number of preclinical studies suggests that pulp stem cells may promote functional recovery after SCI through multifaceted neuroregenerative activities.

\section{Dental pulp stem cells}

Humans have two sets of teeth, 20 deciduous and 32 permanent ones. In the center of each tooth, there is a cavity pulp chamber, which is filled with soft connective tissue called dental pulp (Nanci and Ten Cate, 2003) (Fig.1). The major components of dental pulp are odontoblasts, fibroblasts, immune cells, extracellular matrix, blood vessels and nerve fibers. The pulp tissues are connected with systemic network through the apical foramen; this provides nutrition and sensation for responding to the external stimuli. Human adult dental pulp stem cells (DPSCs) and stem cells from human exfoliated deciduous teeth (SHEDs) are self-renewing stem cells 
residing within the perivascular niche of the dental pulp (Gronthos et al., 2002b). They are thought to originate from the cranial neural crest, of embryonic period and they simultaneously express early markers for both mesenchymal, neuroectodermal stem/progenitor cells and some of embryonic stem cells markers (Gronthos et al., 2000, Miura et al., 2003, Kerkis et al., 2006, Sakai et al., 2012).
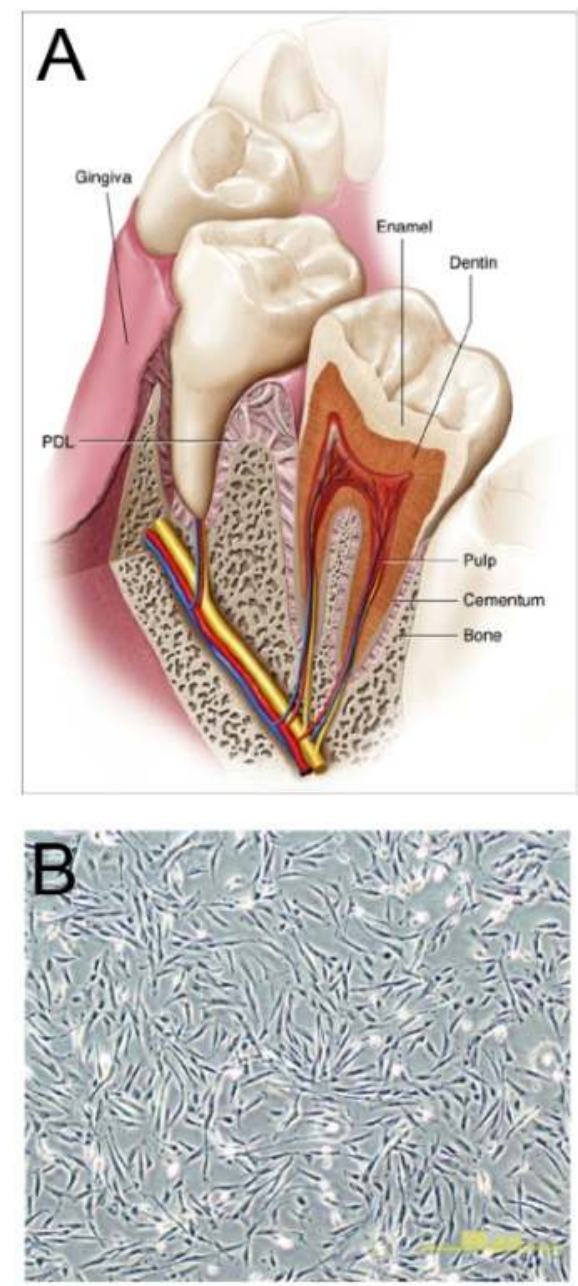

Figure 1. Diagram of tooth and pulp stem cells. (A) The tooth and its supporting structure (from Ten Cate's Oral Histlogy, Nanci and Ten Cate, 2008). PDL, Periodontal ligament. (B) Morphology of pulp stem cells. They exhibit a fibroblastic morphology with a bipolar spindle shape. Scale bar in (B): $500 \mu \mathrm{m}$. 
Most SHEDs and DPSCs express a set of adult bone marrow stromal stem cell (BMSC) markers (CD90, CD73, and CD105), neural stem/progenitor cell markers (Doublecortin, GFAP, and Nestin), and early neuronal and oligodendrocyte markers ( $\beta$ III-tubulin, A2B5 and CNPase), but not markers for mature oligodendrocytes (MBP and APC) (Sakai et al., 2012). Since naturally exfoliated deciduous and impacted adult wisdom teeth are dispensable, DPSCs and SHEDs can be easily obtained by utilizing a simple protocol (Liu et al., 2006). DPSCs and SHEDs exhibit a faster rate of proliferation and a higher number of population doublings in vitro, compared with BMSCs. Furthermore, the rate SHEDs is 1.5 times faster than that of DPSCs (Miura et al., 2003). Like BMSCs, they are multipotent cells that can differentiate in vitro into a variety of cell types including odontoblasts, osteoblasts, chondrocytes, adipocytes, endothelial cells, myocytes, and functionally active neurons (Gronthos et al., 2000, Gronthos et al., 2002a, Batouli et al., 2003, Miura et al., 2003, Nosrat et al., 2004, Kerkis et al., 2006, d'Aquino et al., 2007, Arthur et al., 2008, Arminan et al., 2009, Wang et al., 2010). Furthermore, when transplanted into the transected spinal cord (SC), they specifically differentiate toward mature oligodendrocyte lineages (Sakai et al., 2012: see below).

A cDNA microarray analysis showed that SHEDs express many genes encoding extracellular and cell-surface proteins at levels at least two-fold higher than are expressed in BMSCs (Sakai et al., 2012). It has been shown that the array of trophic factors produced by engrafted DPSCs and SHEDs provide significant therapeutic benefits for the treatment of preclinical animal disease models, including myocardial infarction, systemic lupus erythematosus (SLE), ischemic brain injury, SCI, and colitis (Gandia et al., 2008, Nakashima et al., 2009, Yamaza et al., 2010, de Almeida et al., 2011, Leong et al., 2012, Ma et al., 2012, Sakai et al., 2012, Taghipour et al., 2012, Zhao et al., 2012, Inoue et al., 2013, Yamagata et al., 2013). Thus, these studies collectively show that tooth-derived stem cells are a highly proliferative, multi-potent, and self-renewing ecto-mesenchymal stem cell-like population that actively secretes a broad repertoire of trophic and immunomodulatory factors.

\section{Brief overview of the pathophysiology of SCI}

The development of effective treatments for SCI has been stifled by this injury's complicated pathophysiology. During the acute phase, a primary mechanical insult disrupts tissue homeostasis. This triggers a secondary response, in which activated resident microglia and infiltrating blood-derived macrophages initiate severe inflammation by releasing high levels of multiple neurotoxic factors that induce the necrotic and apoptotic death of neurons, astrocytes, and oligodendrocytes. This response spreads beyond the initial injury site, and leads to irreversible axonal damage and demyelination (Schwab et al., 2006, Popovich and Longbrake, 2008, Rowland et al., 2008). Subsequently, reactive astrocytes and oligodendrocytes near the site of the injured spinal cord (SC) respectively produce chondroitin sulfate proteoglycans (CSPG) and myelin proteins (including myelin-associated glycoprotein (MAG), Nogo, OMG, Netrin, Semaphorin, and Ephrin). These extracellular molecules function as axon growth inhibitors (AGIs), acting through the intracellular Rho GTPase signaling cascade (Silver and Miller, 2004, Yiu and He, 2006). Thus, multiple pathogenic signals act to synergis- 
tically accelerate the progressive neuronal deterioration following SCI. Therefore, therapeutic strategies for functional recovery from SCI must exert multifaceted reparative effects targeting a variety of pathogenic mechanisms (Schwab et al., 2006).

\section{Multifaceted neuro-regenerative activities of pulp stem cells}

\subsection{Anti-inflammatory activity}

Under various pathogenic conditions, macrophages differentiate into polarized pro-inflammatory (M1) or anti-inflammatory (M2) states, and direct either detrimental or beneficial effects on tissue healing (Gordon, 2003, Mosser and Edwards, 2008). In the acute phase of SCI, the majority of accumulating microglia/macrophages are of the M1 type, and few M2 macrophages are seen throughout this period (Kigerl et al., 2009, David and Kroner, 2011). The activated M1 macrophages secrete high levels of pro-inflammatory cytokines and neurotoxic factors, including tumor necrosis factor (TNF)- $\alpha$, interleukin (IL)-1 $\beta$, IL-6, glutamate, and reactive oxygen species (Hausmann, 2003, Donnelly and Popovich, 2008). These neurotoxic factors accelerate glial scar formation (Popovich and Longbrake, 2008), and they induce neuronal cell death (Takeuchi et al., 2006, Block et al., 2007) and the retraction of damaged dystrophic axons (Horn et al., 2008, Busch et al., 2009). In contrast, M2 cells counteract the proinflammatory M1 effects and promote tissue remodeling by secreting anti-inflammatory cytokines (e.g. IL-10 and TGF- $\beta$ ), and scavenging cellular debris (Gordon, 2003, Mosser and Edwards, 2008, David and Kroner, 2011). Thus, macrophage polarity has the potential to determine the level of inflammation and the resultant prognosis following SCI.

Recent studies have demonstrated the induction of M2 macrophage polarization following SCI, and some of the underlying mechanisms are beginning to be elucidated. CSPG, a major component of the glial scar that is mainly known for its ability to inhibit axonal growth, has recently been shown to promote M2 polarization of infiltrating blood-derived macrophages (Rolls et al., 2008, Shechter et al., 2009, Shechter et al., 2011). In addition, recent reports have shown that BMSC transplantation using SCI or brain ischemia models leads to M2 induction (Ohtaki et al., 2008, Nakajima et al., 2012). BMSC-mediated M2 induction requires both the pre-sensitization of BMSCs by pro-inflammatory factors, such as IFN- $\gamma$, TNF- $\alpha$, and LPS, and direct cell-to-cell contact (Nemeth et al., 2009, Singer and Caplan, 2011). Thus, CSPG together with pro-inflammatory factors in the injured SC may be involved in the pre-sensitization of engrafted BMSCs to activate their M2-inducing machinery.

As described in the previous section, SHEDs also exhibit strong immunosuppressive properties that effectively ameliorate several autoimmune diseases, including SLE and colitis (Yamaza et al., 2010, Ma et al., 2012, Zhao et al., 2012). Importantly, intravenously administered SHEDs express Fas-Ligand, which induces T-cell apoptosis, thereby triggering immune tolerance (Zhao et al., 2012). This elevates the ratio of regulatory $\mathrm{T}$ cells (Tregs) to proinflammatory T cells, resulting in anti-inflammatory conditions (Yamaza et al., 2010). We also found that, in the mouse hypoxic ischemia model, both intracerebral transplantation of SHEDs, and administration of serum-free conditioned media (CM) derived from SHEDs (SHED-CM), 
generates anti-inflammatory conditions and promotes functional recovery (Yamagata et al., 2013). Thus, tooth-derived stem cells have strong immunoregulatory properties that promote tissue regeneration in the injured CNS.

\subsection{Regeneration of the injured axon}

Both axonal regeneration and the re-formation of appropriate neuronal connections are required for functional recovery from SCI. However, multiple AGIs block the inherent regenerative capacities of injured axons (Silver and Miller, 2004, Schwab et al., 2006, Yiu and $\mathrm{He}, 2006$, Rowland et al., 2008). It is well known that AGIs constitute an intricate molecular network in the extracellular space of the injured CNS, where they activate a common intracellular signaling mediator, Rho GTPase, and its effector, Rho-associated kinase (ROCK) (Maekawa et al., 1999, Winton et al., 2002, Dubreuil et al., 2003, Monnier et al., 2003, Yamashita and Tohyama, 2003). Activation of the Rho-ROCK cascade induces growth-cone collapse and axonal repulsion (Hall, 1998). In contrast, inactivation of either Rho by C3 transferase, or ROCK by the kinase inhibitor Y-27632 down-regulates AGI signaling and promotes functional recovery after SCI (Lehmann et al., 1999, Dergham et al., 2002, Fournier et al., 2003). Thus, RhoROCK signaling is an important target for SCI treatments; however, few studies have investigated the effect of stem-cell transplantation on regulating AGI/Rho-ROCK signaling cascades.

Importantly, engrafted SHEDs were recently shown to promote the regeneration of two major types of descending axons (CST and 5-HT) beyond the lesion epicenter, and to concomitantly inhibit SCI-induced Rho activation. Furthermore, both SHED-CM and DPSC-CM (but not BMSC-CM) promote neurite extension by primary cerebral granular neurons (CGNs) cultured on two different AGIs (CSPG and MAG) (Sakai et al., 2012). Thus, tooth-derived stem cells promote the regeneration of transected axons through the direct inhibition of multiple AGI signals by paracrine mechanisms.

In addition, the engraftment of DPSCs into avian embryos results in the chemoattraction of trigeminal ganglion axons via the chemokine CXCL12 and its receptor, CXCR4 (Arthur et al., 2009). DPSCs and SHEDs express several neurotropic factors that promote neurite extension (de Almeida et al., 2011, Sakai et al., 2012). Our preliminary analysis showed that these trophic factors, when applied individually, failed to promote the neurite extension of CGNs cultured on CSPG-coated dishes; however it is possible that they may promote axonal regeneration in a synergistic manner.

\subsection{Anti-apoptotic activity}

Pharmacological blockade of neuron and/or oligodendrocyte apoptosis by a number of agents promotes functional recovery after SCI. These agents include the following: erythropoietin (Celik et al., 2002, Gorio et al., 2002), inhibitors of purine receptor P2X7 (OxATP and PPADS) (Wang et al., 2004), a neutralizing antibody against CD95 (FAS) antigen (Demjen et al., 2004), and minocycline (Stirling et al., 2004, Teng et al., 2004). Engrafted SHEDs suppress the apoptosis of neurons and oligodendrocytes, resulting in the remarkable preservation of 
neurofilaments and myelin sheaths in the region surrounding the lesion epicenter (Nosrat et al., 2001, de Almeida et al., 2011). Intracerebral transplantation of DPSCs from rhesus macaques promotes proliferation, cell recruitment, and maturation of endogenous stem/progenitor cells by modulating the local microenvironment (Huang et al., 2008). Notably, SHEDs also strongly inhibit the apoptosis of astrocytes recruited to the lesion (Sakai et al., 2012).

Classically, reactive, CSPG-generating astrocytes have been considered an obstacle to axonal regeneration; however, recent genetic studies in mice indicate that the conditional ablation of astrocytes after SCI results in larger lesions, failure of blood-brain-barrier repair, increased inflammation and tissue disruption, severe demyelination, and profound cell death of neurons and oligodendrocytes (Bush et al., 1999, Faulkner et al., 2004, Okada et al., 2006, Herrmann et al., 2008, Rolls et al., 2009). Thus, the collective evidence demonstrates that, in addition to their anti-regenerative activity, astrocytes also play an important role in neuro-protection during the acute phase of SCI. SHEDs can suppress astrocyte apoptosis and minimize secondary injury, as well as inhibit the AGI activity of CSPG derived from astrocytes. Thus, SHEDs have the potential to promote functional recovery after SCI through two distinct mechanisms involving astrocyte regulation.

\subsection{Cell-replacement activity}

Undifferentiated rat and human pulp stem cells can form neurospheres in vitro (Sasaki et al., 2008, Wang et al., 2010) and simultaneously express multiple neural stem/progenitor markers (Gronthos et al., 2002a, Miura et al., 2003, Sakai et al., 2012). In addition, DPSCs can differentiate in vitro toward functionally active neurons, which express voltage-gated $\mathrm{Na}+$ channels, and in vivo toward neuron-like cells 48 hours after transplantation into the mesencephalon of avian embryos (Arthur et al., 2008). Furthermore, simultaneous PKC and cAMP activation induces the differentiation of DPSCs into functionally active neurons (Kiraly et al., 2009). Thus, pulp stem cells display a capacity for neuronal differentiation both in vivo and in vitro.

Recently, three independent groups reported that pulp stem cells show neuro-regenerative activity in rodent SCI models. Interestingly, engrafted pulp stem cells promoted significant functional recovery in all three studies, but exhibited variable capacities for differentiation. In the first study, DPSCs were transplanted into the compressed mouse SC at day 7 (sub-acute phase) or day 28 (chronic phase) after injury, and the engrafted DPSCs differentiated into glia cells expressing S-100 and GFAP (de Almeida et al., 2011). In the second study, undifferentiated or neural-phenotype induced SHED (iSHED) were transplanted into the contused rat SC at 7 days after injury. Engrafted SHED and iSHED differentiated primarily into MAP2+mature neurons and GFAP+astrocytes, and to a lesser extent into MBP-and NG2-expressing oligodendrocytes (Taghipour et al., 2012). In the third study, from our group, undifferentiated SHEDs were transplanted into the completely transected rat SC immediately after the surgery. The engrafted SHEDs survived well following SCI: more than $30 \%$ of the engrafted SHEDs survived as a cell mass in the injured SC 8 weeks after transplantation and more than $90 \%$ of the engrafted SHEDs differentiated toward mature oligodendrocytes, expressing APC and MBP (Sakai et al., 2012). 
Taken together, these experimental data suggest that the microenvironment of the transplanted stem cells significantly affects their capacity for differentiation. In the acute phase of SCI, the injured SC contains high levels of pro-inflammatory mediators. Thus these factors may activate the oligodendrocyte-specific differentiation cascade of pulp stem cells.

\section{Conclusion}

Recent experimental data from a number of studies reveals that engrafted SHEDs provide a number of distinct therapeutic benefits for treatment of SCI: (1) the suppression of the early inflammatory response; (2) inhibition of the SCI-induced apoptosis of neurons, astrocytes, and oligodendrocytes, which promotes the preservation of neural fibers and myelin sheaths; (3) regeneration of the transected axon through the direct inhibition of multiple AGI signals (including CSPG and MAG) by paracrine mechanisms; and (4) cell replacement in the damaged SC through the SHEDs' capacity for differentiation towards oligodendrocytes, neurons and astrocytes. Thus, we propose that tooth-derived stem cells may provide significant therapeutic benefits for treating SCI through both cell-autonomous and paracrine/trophic regenerative activities.

\section{Acknowledgements}

This work was supported by grants from Ministry of Education, Culture, Sports, Science and Technology.

\section{Author details}

Akihito Yamamoto, Kohki Matsubara, Kiyoshi Sakai, Fumiya Kano and Minoru Ueda

Nagoya University Graduate School of Medicine, Japan

\section{References}

[1] Arminan A, Gandia C, Bartual M, Garcia-Verdugo JM, Lledo E, Mirabet V, Llop M, Barea J, Montero JA, Sepulveda P (2009) Cardiac differentiation is driven by NKX2.5 and GATA4 nuclear translocation in tissue-specific mesenchymal stem cells. Stem Cells Dev 18:907-918. 
[2] Arthur A, Rychkov G, Shi S, Koblar SA, Gronthos S (2008) Adult Human Dental Pulp Stem Cells Differentiate Toward Functionally Active Neurons Under Appropriate Environmental Cues. Stem Cells 26:1787-1795.

[3] Arthur A, Shi S, Zannettino ACW, Fujii N, Gronthos S, Koblar SA (2009) Implanted adult human dental pulp stem cells induce endogenous axon guidance. Stem Cells 27:2229-2237.

[4] Batouli S, Miura M, Brahim J, Tsutsui TW, Fisher LW, Gronthos S, Robey PG, Shi S (2003) Comparison of stem-cell-mediated osteogenesis and dentinogenesis. J Dent Res 82:976-981.

[5] Block ML, Zecca L, Hong JS (2007) Microglia-mediated neurotoxicity: uncovering the molecular mechanisms. Nat Rev Neurosci 8:57-69.

[6] Busch S, Horn K, Silver D, Silver J (2009) Overcoming Macrophage-Mediated Axonal Dieback Following CNS Injury. J Neurosci 29:9967.

[7] Bush TG, Puvanachandra N, Horner CH, Polito A, Ostenfeld T, Svendsen CN, Mucke L, Johnson MH, Sofroniew MV (1999) Leukocyte infiltration, neuronal degeneration, and neurite outgrowth after ablation of scar-forming, reactive astrocytes in adult transgenic mice. Neuron 23:297-308.

[8] Celik M, Gokmen N, Erbayraktar S, Akhisaroglu M, Konakc S, Ulukus C, Genc S, Genc K, Sagiroglu E, Cerami A, Brines M (2002) Erythropoietin prevents motor neuron apoptosis and neurologic disability in experimental spinal cord ischemic injury. Proc Natl Acad Sci USA 99:2258-2263.

[9] d'Aquino R, Graziano A, Sampaolesi M, Laino G, Pirozzi G, De Rosa A, Papaccio G (2007) Human postnatal dental pulp cells co-differentiate into osteoblasts and endotheliocytes: a pivotal synergy leading to adult bone tissue formation. Cell Death Differ 14:1162-1171.

[10] David S, Kroner A (2011) Repertoire of microglial and macrophage responses after spinal cord injury. Nat Rev Neurosci 12:388-399.

[11] de Almeida FM, Marques SA, Ramalho Bdos S, Rodrigues RF, Cadilhe DV, Furtado D, Kerkis I, Pereira LV, Rehen SK, Martinez AM (2011) Human dental pulp cells: a new source of cell therapy in a mouse model of compressive spinal cord injury. J Neurotrauma 28:1939-1949.

[12] Demjen D, Klussmann S, Kleber S, Zuliani C, Stieltjes B, Metzger C, Hirt U, Walczak H, Falk W, Essig M, Edler L, Krammer P, Martin-Villalba A (2004) Neutralization of CD95 ligand promotes regeneration and functional recovery after spinal cord injury. Nat Med 10:389-395.

[13] Dergham P, Ellezam B, Essagian C, Avedissian H, Lubell WD, McKerracher L (2002) Rho signaling pathway targeted to promote spinal cord repair. J Neurosci 22:6570-6577. 
[14] Donnelly DJ, Popovich PG (2008) Inflammation and its role in neuroprotection, axonal regeneration and functional recovery after spinal cord injury. Exp Neurol 209:378-388.

[15] Dubreuil C, Winton M, McKerracher L (2003) Rho activation patterns after spinal cord injury and the role of activated Rho in apoptosis in the central nervous system. J Cell Biol 162:233-243.

[16] Faulkner JR, Herrmann JE, Woo MJ, Tansey KE, Doan NB, Sofroniew MV (2004) Reactive astrocytes protect tissue and preserve function after spinal cord injury. J Neurosci 24:2143-2155.

[17] Fournier AE, Takizawa BT, Strittmatter SM (2003) Rho kinase inhibition enhances axonal regeneration in the injured CNS. J Neurosci 23:1416-1423.

[18] Gandia C, Arminan A, Garcia-Verdugo JM, Lledo E, Ruiz A, Minana MD, SanchezTorrijos J, Paya R, Mirabet V, Carbonell-Uberos F, Llop M, Montero JA, Sepulveda P (2008) Human dental pulp stem cells improve left ventricular function, induce angiogenesis, and reduce infarct size in rats with acute myocardial infarction. Stem Cells 26:638-645.

[19] Gordon S (2003) Alternative activation of macrophages. Nature Reviews Immunology 3:23-35.

[20] Gorio A, Gokmen N, Erbayraktar S, Yilmaz O, Madaschi L, Cichetti C, Di Giulio A, Vardar E, Cerami A, Brines M (2002) Recombinant human erythropoietin counteracts secondary injury and markedly enhances neurological recovery from experimental spinal cord trauma. Proc Natl Acad Sci USA 99:9450-9455.

[21] Gronthos S, Brahim J, Li W, Fisher LW, Cherman N, Boyde A, DenBesten P, Robey PG, Shi S (2002a) Stem cell properties of human dental pulp stem cells. J Dent Res 81:531-535.

[22] Gronthos S, Brahim J, Li W, Fisher LW, Cherman N, Boyde A, Denbesten P, Robey PG, Shi S (2002b) Stem Cell Properties of Human Dental Pulp Stem Cells. J Dent Res 81:531-535.

[23] Gronthos S, Mankani M, Brahim J, Robey PG, Shi S (2000) Postnatal human dental pulp stem cells (DPSCs) in vitro and in vivo. Proc Natl Acad Sci USA 97:13625-13630.

[24] Hall A (1998) Rho GTPases and the actin cytoskeleton. Science 279:509-514.

[25] Hausmann ON (2003) Post-traumatic inflammation following spinal cord injury. Spinal Cord 41:369-378.

[26] Herrmann JE, Imura T, Song B, Qi J, Ao Y, Nguyen TK, Korsak RA, Takeda K, Akira S, Sofroniew MV (2008) STAT3 is a critical regulator of astrogliosis and scar formation after spinal cord injury. J Neurosci 28:7231-7243. 
[27] Horn K, Busch S, Hawthorne A, Van Rooijen N, Silver J (2008) Another Barrier to Regeneration in the CNS: Activated Macrophages Induce Extensive Retraction of Dystrophic Axons through Direct Physical Interactions. J Neurosci 28:9330.

[28] Huang AH-C, Snyder BR, Cheng P-H, Chan AWS (2008) Putative dental pulp-derived stem/stromal cells promote proliferation and differentiation of endogenous neural cells in the hippocampus of mice. Stem Cells 26:2654-2663.

[29] Inoue T, Sugiyama M, Hattori H, Wakita H, Wakabayashi T, Ueda M (2013) Stem cells from human exfoliated deciduous tooth-derived conditioned medium enhance recovery of focal cerebral ischemia in rats. Tissue engineering Part A 19:24-29.

[30] Kerkis I, Kerkis A, Dozortsev D, Stukart-Parsons GC, Gomes Massironi SM, Pereira LV, Caplan AI, Cerruti HF (2006) Isolation and characterization of a population of immature dental pulp stem cells expressing OCT-4 and other embryonic stem cell markers. Cells Tissues Organs 184:105-116.

[31] Kigerl KA, Gensel JC, Ankeny DP, Alexander JK, Donnelly DJ, Popovich PG (2009) Identification of two distinct macrophage subsets with divergent effects causing either neurotoxicity or regeneration in the injured mouse spinal cord. The Journal of neuroscience 29:13435-13444.

[32] Kiraly M, Porcsalmy B, Pataki A, Kadar K, Jelitai M, Molnar B, Hermann P, Gera I, Grimm WD, Ganss B, Zsembery A, Varga G (2009) Simultaneous PKC and cAMP activation induces differentiation of human dental pulp stem cells into functionally active neurons. Neurochem Int 55:323-332.

[33] Lehmann M, Fournier A, Selles-Navarro I, Dergham P, Sebok A, Leclerc N, Tigyi G, McKerracher L (1999) Inactivation of Rho signaling pathway promotes CNS axon regeneration. J Neurosci 19:7537-7547.

[34] Leong WK, Henshall TL, Arthur A, Kremer KL, Lewis MD, Helps SC, Field J, Hamilton-Bruce MA, Warming S, Manavis J, Vink R, Gronthos S, Koblar SA (2012) Human adult dental pulp stem cells enhance poststroke functional recovery through nonneural replacement mechanisms. Stem cells translational medicine 1:177-187.

[35] Liu H, Gronthos S, Shi S (2006) Dental pulp stem cells. Methods Enzymol 419:99-113.

[36] Ma L, Makino Y, Yamaza H, Akiyama K, Hoshino Y, Song G, Kukita T, Nonaka K, Shi S, Yamaza T (2012) Cryopreserved dental pulp tissues of exfoliated deciduous teeth is a feasible stem cell resource for regenerative medicine. PLoS One 7:e51777.

[37] Maekawa M, Ishizaki T, Boku S, Watanabe N, Fujita A, Iwamatsu A, Obinata T, Ohashi K, Mizuno K, Narumiya S (1999) Signaling from Rho to the actin cytoskeleton through protein kinases ROCK and LIM-kinase. Science 285:895-898.

[38] Miura M, Gronthos S, Zhao M, Lu B, Fisher LW, Robey PG, Shi S (2003) SHED: stem cells from human exfoliated deciduous teeth. Proc Natl Acad Sci USA 100:5807-5812. 
[39] Monnier PP, Sierra A, Schwab JM, Henke-Fahle S, Mueller BK (2003) The Rho/ROCK pathway mediates neurite growth-inhibitory activity associated with the chondroitin sulfate proteoglycans of the CNS glial scar. Mol Cell Neurosci 22:319-330.

[40] Mosser DM, Edwards JP (2008) Exploring the full spectrum of macrophage activation. Nat Rev Immunol 8:958-969.

[41] Nakajima H, Uchida K, Rodriguez Guerrero A, Watanabe S, Sugita D, Takeura N, Yoshida A, Long G, Wright K, Johnson E, Baba H (2012) Transplantation of Mesenchymal Stem Cells Promotes the Alternative Pathway of Macrophage Activation and Functional Recovery after Spinal Cord Injury. J Neurotrauma.

[42] Nakashima M, Iohara K, Sugiyama M (2009) Human dental pulp stem cells with highly angiogenic and neurogenic potential for possible use in pulp regeneration. Cytokine Growth Factor Rev 20:435-440.

[43] Nanci A, Ten Cate AR (2003) Ten Cate's oral histology : development, structure, and function. St. Louis, Mo. ; London: Mosby.

[44] Nanci A, Ten Cate AR (2008) Ten Cate's oral histology : development, structure, and function. St. Louis, Mo.: Mosby.

[45] Nemeth K, Leelahavanichkul A, Yuen PS, Mayer B, Parmelee A, Doi K, Robey PG, Leelahavanichkul K, Koller BH, Brown JM, Hu X, Jelinek I, Star RA, Mezey E (2009) Bone marrow stromal cells attenuate sepsis via prostaglandin E(2)-dependent reprogramming of host macrophages to increase their interleukin-10 production. Nat Med 15:42-49.

[46] Nosrat IV, Smith CA, Mullally P, Olson L, Nosrat CA (2004) Dental pulp cells provide neurotrophic support for dopaminergic neurons and differentiate into neurons in vitro; implications for tissue engineering and repair in the nervous system. Eur J Neurosci 19:2388-2398.

[47] Nosrat IV, Widenfalk J, Olson L, Nosrat CA (2001) Dental pulp cells produce neurotrophic factors, interact with trigeminal neurons in vitro, and rescue motoneurons after spinal cord injury. Dev Biol 238:120-132.

[48] Ohtaki H, Ylostalo JH, Foraker JE, Robinson AP, Reger RL, Shioda S, Prockop DJ (2008) Stem/progenitor cells from bone marrow decrease neuronal death in global ischemia by modulation of inflammatory/immune responses. Proc Natl Acad Sci U S A 105:14638-14643.

[49] Okada S, Nakamura M, Katoh H, Miyao T, Shimazaki T, Ishii K, Yamane J, Yoshimura A, Iwamoto Y, Toyama Y, Okano H (2006) Conditional ablation of Stat3 or Socs3 discloses a dual role for reactive astrocytes after spinal cord injury. Nat Med 12:829-834.

[50] Popovich PG, Longbrake EE (2008) Can the immune system be harnessed to repair the CNS? Nat Rev Neurosci 9:481-493. 
[51] Rolls A, Shechter R, London A, Segev Y, Jacob-Hirsch J, Amariglio N, Rechavi G, Schwartz M (2008) Two faces of chondroitin sulfate proteoglycan in spinal cord repair: a role in microglia/macrophage activation. PLoS Med 5:e171.

[52] Rolls A, Shechter R, Schwartz M (2009) The bright side of the glial scar in CNS repair. Nat Rev Neurosci 10:235-241.

[53] Rowland JW, Hawryluk GWJ, Kwon B, Fehlings MG (2008) Current status of acute spinal cord injury pathophysiology and emerging therapies: promise on the horizon. Neurosurg Focus 25:E2.

[54] Sakai K, Yamamoto A, Matsubara K, Nakamura S, Naruse M, Yamagata M, Sakamoto K, Tauchi R, Wakao N, Imagama S, Hibi H, Kadomatsu K, Ishiguro N, Ueda M (2012) Human dental pulp-derived stem cells promote locomotor recovery after complete transection of the rat spinal cord by multiple neuro-regenerative mechanisms. The Journal of clinical investigation 122:80-90.

[55] Sasaki R, Aoki S, Yamato M, Uchiyama H, Wada K, Okano T, Ogiuchi H (2008) Neurosphere generation from dental pulp of adult rat incisor. Eur J Neurosci 27:538-548.

[56] Schwab JM, Brechtel K, Mueller CA, Failli V, Kaps HP, Tuli SK, Schluesener HJ (2006) Experimental strategies to promote spinal cord regeneration--an integrative perspective. Prog Neurobiol 78:91-116.

[57] Shechter R, London A, Varol C, Raposo C, Cusimano M, Yovel G, Rolls A, Mack M, Pluchino S, Martino G, Jung S, Schwartz M (2009) Infiltrating blood-derived macrophages are vital cells playing an anti-inflammatory role in recovery from spinal cord injury in mice. PLoS Med 6:e1000113.

[58] Shechter R, Raposo C, London A, Sagi I, Schwartz M (2011) The glial scar-monocyte interplay: a pivotal resolution phase in spinal cord repair. PLoS One 6:e27969.

[59] Silver J, Miller JH (2004) Regeneration beyond the glial scar. Nat Rev Neurosci 5:146-156.

[60] Singer NG, Caplan AI (2011) Mesenchymal stem cells: mechanisms of inflammation. Annu Rev Pathol 6:457-478.

[61] Stirling DP, Khodarahmi K, Liu J, McPhail LT, McBride CB, Steeves JD, Ramer MS, Tetzlaff W (2004) Minocycline treatment reduces delayed oligodendrocyte death, attenuates axonal dieback, and improves functional outcome after spinal cord injury. J Neurosci 24:2182-2190.

[62] Taghipour Z, Karbalaie K, Kiani A, Niapour A, Bahramian H, Nasr-Esfahani MH, Baharvand $H$ (2012) Transplantation of undifferentiated and induced human exfoliated deciduous teeth-derived stem cells promote functional recovery of rat spinal cord contusion injury model. Stem Cells Dev 21:1794-1802.

[63] Takeuchi H, Jin S, Wang J, Zhang G, Kawanokuchi J, Kuno R, Sonobe Y, Mizuno T, Suzumura A (2006) Tumor necrosis factor-alpha induces neurotoxicity via glutamate 
release from hemichannels of activated microglia in an autocrine manner. J Biol Chem 281:21362-21368.

[64] Teng YD, Choi H, Onario RC, Zhu S, Desilets FC, Lan S, Woodard EJ, Snyder EY, Eichler ME, Friedlander RM (2004) Minocycline inhibits contusion-triggered mitochondrial cytochrome c release and mitigates functional deficits after spinal cord injury. Proc Natl Acad Sci USA 101:3071-3076.

[65] Wang J, Wang X, Sun Z, Wang X, Yang H, Shi S, Wang S (2010) Stem cells from human-exfoliated deciduous teeth can differentiate into dopaminergic neuron-like cells. Stem Cells Dev 19:1375-1383.

[66] Wang X, Arcuino G, Takano T, Lin J, Peng W, Wan P, Li P, Xu Q, Liu Q, Goldman S, Nedergaard M (2004) P2X7 receptor inhibition improves recovery after spinal cord injury. Nat Med 10:821-827.

[67] Winton MJ, Dubreuil CI, Lasko D, Leclerc N, McKerracher L (2002) Characterization of new cell permeable C3-like proteins that inactivate Rho and stimulate neurite outgrowth on inhibitory substrates. J Biol Chem 277:32820-32829.

[68] Yamagata M, Yamamoto A, Kako E, Kaneko N, Matsubara K, Sakai K, Sawamoto K, Ueda M (2013) Human dental pulp-derived stem cells protect against hypoxic-ischemic brain injury in neonatal mice. Stroke 44:551-554.

[69] Yamashita T, Tohyama M (2003) The p75 receptor acts as a displacement factor that releases Rho from Rho-GDI. Nat Neurosci 6:461-467.

[70] Yamaza T, Kentaro A, Chen C, Liu Y, Shi Y, Gronthos S, Wang S, Shi S (2010) Immunomodulatory properties of stem cells from human exfoliated deciduous teeth. Stem cell research \& therapy 1:5.

[71] Yiu G, He Z (2006) Glial inhibition of CNS axon regeneration. Nat Rev Neurosci 7:617-627.

[72] Zhao Y, Wang L, Jin Y, Shi S (2012) Fas ligand regulates the immunomodulatory properties of dental pulp stem cells. J Dent Res 91:948-954. 
